\title{
Inflation and Financial Development: Evidence
}

\author{
Emmanuel Nii Abbey \\ Department of Economics, Faculty of Social Science, University of Ghana, Legon-Ghana
}

\begin{abstract}
The study examined the impact of inflation on financial development in Ghana using quarterly time series data (1990-2008). It was in line with the empirical works that provided support for the proposition that inflation affects financial development negatively. While price stability has been emphasized in the literature to be the best antidote in addressing the problem, recent evidence of disagreements on its definition and the ways to achieving it, coupled with, threshold effects between the two variables have questioned the precise link between the two variables and their acclaimed antidote. The study therefore made use of the Cointegration Approach the Granger Causality testing procedure suggested and the Conditional Least Squares technique to address these issues for the case of Ghana. The study established several statistically significant and economically meaningful relationships between the two variables. Pair-wise correlation analysis established a negative association between the two variables. In contrast, conflicting results were produced with regression analysis: the relationship between the two variables in the short run was established to be positive, while no relationship at all was established in the long run. Furthermore, a unidirectional causal link was established to be running from inflation to financial development; when the ratio of private sector credit to GDP and the market capitalization ratio were used as indicators for financial development. Lastly, threshold effects were observed in the inflation-financial development relation for inflation rates between $11-16 \%$ per annum. The study thus recommended the definition of price stability for inflation rates between 11-16\% in support of financial development in Ghana. Additionally, it was recommended that the country should promote financial sector policies in a more holistic approach, as financial development does not granger cause inflation or inflationary pressures.
\end{abstract}

Keywords: Inflation, Financial Development, Cointegration, Threshold Effects, Causality

\section{INTRODUCTION}

The study of the interrelationship between inflation and financial development has become an important issue for monetary authorities in recent times given the current emphasis on inflation targeting as the primary monetary policy framework. Though the theoretical positions on the subject are diverse, a considerably large body of empirical works has provided support for the proposition that inflation affects financial development negatively, thus price stability must be an essential precondition for successful financial development (Boyd et al., 1996; 2001; Ghazouani, 2005; Khan and Senhadji, 2001; Bittencourt, 2008; Huang et al., 2010; Keho, 2009). While this suggestion appears legitimate and reasonably satisfactory, less agreement exists amongst many monetary authorities on its definition and consequently the ways to achieving it. Papademos (2006), for instance, defines price stability as "a state in which the general price level is literally stable or the inflation rate is sufficiently low and stable, so that considerations concerning the nominal dimension of transactions cease to be a pertinent factor for economic decisions". Similarly, Volcker (1983) considers price stability as a "situation in which expectations of generally rising (or falling) prices over a considerable period are not a pervasive influence on economic and financial behaviour". Additionally, Greenspan (1996) believes price stability occurs when "economic agents no longer take account of the 
prospective change in the general price level in their economic decision making". Consequently, the European Central Bank sees price stability as an increase in the general level of prices of less than $2 \%$. Acquah (2005a), a former governor of the BG (2002) sees an average inflation rate of some $20 \%$ a year, over a ten-year period, of not falling within the definition of price stability. From an operational point of view, Fischer $(1996 ; 1983)$ believes price stability represents an inflation rate between 0-3\%. Lastly, Meltzer (1997) sees price stability as an inflation rate so close to zero.

These disagreements notwithstanding, monetary authorities across the world still emphasize price stability as an essential pillar of modern monetary policy operation, since it not only creates the necessary conditions for successful financial development, but also is a means to an end-it also promotes economic growth, job creation and social cohesion (McDonough, 1997; Acquah, 2005b).

Recent interest in the literature explaining the inflation-financial development link is the search for certain critical levels (threshold levels) of inflation, above which inflation affects financial development differently than below and subsequently, affecting important economic variables, particularly economic growth (Boyd et al., 1996; Keho, 2009). Boyd et al. (1996), for instance, argue that if the current rate of inflation exceeds such critical levels (threshold levels) of inflation, high steady state activity cannot be achieved and financial markets frictions become relatively more severe, further inducing endogenously arising volatility (instability) in important economic variables. This suggests that though price stability might be an essential precondition for successful financial development, knowing such critical levels of inflation also add light to addressing the adverse impact of inflation on financial.

In Ghana, though price stability has long been an essential monetary policy objective (for the most part of the late 1990 and the 2000) for the effective and efficient operation of financial institutions, the extent of financial development in the country still appear to be marginal. Gockel and Akoena (2002) in fact described banking in Ghana as urbanized and elitist with the marginalization of local enterprises from the credit market. With much not changing in recent times, the extent to which price stability has been defined and the framework to achieving it in the country has been questioned as inflation has been following a drastic downward trend $(70.82 \%$ in $1995-10.82 \%$ in 2006) and financial development has only responded marginally.

This question falls within the realm of the long standing debate on the mechanisms through which the adverse link between inflation and economic growth could be addressed through the financial sector, giving the positive correlation between financial development and economic growth. Evidence has it that the way inflation hurts economic growth was by its interference with the role financial intermediaries' actively play in an economy. This is the case as high rates of inflation negatively affect developments in the financial system, exacerbate credit market frictions and ultimately, make financial institutions inefficient in allocating resources for growth (Huybens and Smith, 1998; 1999; Boyd and Smith, 1998). It may therefore be prudent for the exact links between inflation and financial development to be explored, so that the right mechanisms will be put in place in addressing the adverse link between inflation and economic growth. This is accomplished, for the case of Ghana, by incorporating a combination of marketbased and bank-based indicators of financial development to enable a fair comparison.

\subsection{Literature Review}

Broadly, Boyd et al. (1996) identified three general classes of theoretical models that confront the inflation-financial development link pretty well and relevant to this study.

First, there was a class in which financial markets' efficiency affects the allocation of savings and investment in the presence of various informational asymmetries (Stiglitz and Weiss, 1981; Boyd et al., 1996; Huybens and Smith, 1998). In these models, high rates of inflation exacerbate financial markets friction, interfere with the efficiency of the financial system and hamper long run growth. These models, once more, generate development traps and threshold effects. Boyd et al. (1996), for instance, argue that there may be multiple steady states in such cases-some with high and others with low levels of real activity-such that in high (low) activity steady states, financial market frictions confronting the economy are relatively mild (severe). Additionally, they argue that at lower rates of inflation, both low and high activity steady states could be approached; however, at higher rates of inflation, access to high activity steady states is unstable. Boyd et al. (1996) thus suggested certain critical levels of inflation, such that if the inflation rate exceeds such critical levels (threshold levels) high steady state activity cannot be approached and financial markets friction becomes relatively more severe. They further predicted high rates of inflation can induce endogenously arising volatility (instabilities) in important economic variables including equity returns 
and that high rates of inflation will be associated with low real returns to saving.

Second, there was a class that focuses on the behaviour of a government confronted with the necessity of financing a deficit (McKinnon, 1973; 1982; Bencivenga and Smith, 1992). Such governments, often with large deficits and large seigniorage revenue needs may-for optimal taxation reasons-take actions to increase their inflation tax base. They thus rely heavily on inflationary taxation and also take actions to tax the financial system. These accounts for a negative correlation between inflation and the level of activities in the financial market, since more demand for seigniorage revenue by such governments imply a higher tax claim on the financial market and this disrupts their activities. In addition, such models predict that governments should intervene in the financial market-with various policies (mostly fiscal)only when deficits (and inflation) exceed a certain critical level (Bencivenga et al., 1995). This class of models, therefore, potentially predict the same kind of threshold effects observed in the earlier class of models.

Lastly, there was a class that perceives financial development as a normal good and economic growth, a variable that naturally engenders a more developed financial system (Boyd et al., 1996). In these models, high real growth rates imply a lower rate of inflation, all other things being equal inflation and financial market performance may be correlated only because economic growth, whose source may be sought elsewhere, affects both.

From an empirical point of view, studies examining the impact of inflation on financial development (based on cross-sectional, panel and time series analysis) generally show a strong and a statistically significant negative relationship (correlation) between the variables. The direction of causality, though not explicitly stated, is usually from inflation to financial development. Lastly, a threshold level of inflation was identified, above which inflation affects financial development differently than below. A few of such studies are discussed in the subsequent paragraphs.

To begin with, Bittencourt (2008) examined the impact of inflation on financial development in Brazil between 1985 and 2002. The results of his study-based initially on time-series data and then on panel time-series data and performing analysis which was robust for different estimators and financial development measuressuggest inflation presents deleterious effects to financial development. The study therefore suggests poor macroeconomic performances has detrimental effects on financial development; a variable that was important in affecting, for example, economic growth and income inequality. Therefore, a low and stable inflation rate all that it encompasses, was a necessary first step to achieving a deeper and more active financial sector with all its attached benefits.

Al-Nasser and Jackson (2012) also employed a panel data methodology on pooled data for 15 Latin American countries from 1978-2003 to empirically examine the long run link between inflation and financial sector performance. Focusing entirely on the banking sector as well as the stock markets, they established that there was a negative and statistically significant relationship between banking sector development measures and the level of inflation after controlling for other economic factors that may be associated with financial development. Again, they established that inflation was negatively correlated with market capitalization and domestic value traded; which indicates that higher inflation rates depress stock market development in Latin American countries. These results implied that macroeconomic stability should be a primary objective for monetary policy since high inflation is shown to be economically costly (in the form of reduced economic growth rates and the international competitiveness of a country).

Boyd et al. (2001) broadened the study of the link between inflation and financial development by investigating 100 different countries to assess the predictions about the mechanisms by which predictable increases in the rate of inflation interfere with the ability of the financial sector to allocate resources effectively. They employed a panel methodology on time series data for inflation, banking sector activity, equity market size, equity market liquidity the rates of return over the period 1960-1995. Their study indicated that there was a significant and non-linear negative relationship between inflation and both banking sector development and equity market activity. Moreover, they find evidence of threshold effects in the inflation-financial development link for the 100 different Latin American Countries; for instance, they established that a discrete drop in financial performance for economies with inflation rates exceeding $15 \%$. Finally, their data indicated that more inflation was not matched by greater nominal equity returns in low-inflation countries, thus nominal stock returns move essentially one-for-one with marginal increases in inflation in high-inflation economies.

Ghazouani (2005) extended the work by Boyd et al. (2001) to 11 MENA (Middle East and North African Countries) regions by constructing a dynamic panel model for data spanning 1979-1999 and employed the Generalized Methods of Moment proposed by Arellano and Bond to examine the impact of inflation on financial 
sector performance. Ghazouani (2005) extension indicated that inflation had a negative and significant incidence on financial sector development; but there was no evidence of thresholds, even after controlling for simultaneity and omitted variable biases. In other words, he showed that a marginal increase of inflation is harmless to stock market performance and banking sector development; whatever the rate of inflation.

In a different context, Huang et al. (2010) investigated whether there are any inflationary thresholds in the finance-growth linkage. By applying the Caner and Hansen (2004) instrumental-variable threshold regression approach to the dataset of Levine et al. (2000), they find strong evidence of a nonlinear inflation threshold in the relationship; below which financial development exerts a significantly positive effect on economic growth, above which, the growth effect of finance appears to be insignificant. Furthermore, they established a positive and significant relationship between finance and productivity for inflation rates below the threshold level. They however did not find any such relationship for inflation rates above the threshold level. The results suggested that finance influences growth mainly through the productivity channel.

Khan et al. (2001) using a large cross-country sample, found an empirical support for the existence of a threshold level of inflation; generally of about 3-6\% per annum depending on the specific measure of financial depth utilized. For rates of inflation below the threshold level, modest increases in the rate of inflation either had no significant effect on financial market conditions or had small positive effects on the level of financial activity (also depending of the indicator of financial depth used). However, for rates of inflation above the threshold level, increases in the rate of inflation has a strong negative effect on financial development. Given what is known about the relationship between financial markets and growth (following the supply leading hypothesis), it is then not surprising that high rates of inflation are detrimental to growth.

Keho (2009) used time-series data to examine the long-run and causal relationships between inflation and financial development for the UEMOA countries. Using the bounds test cointegration approach proposed by Pesaran et al. (2001) and the Granger causality test suggested by Toda and Yamamoto (1995), he obtained empirical results showing no evidence of a long-run relationship between inflation and financial development for six countries (as against one) and no causality for two countries (as against five). Again he established that financial development causes inflation in four countries; while evidence of a reverse causation was detected for only two countries. His findings, however, showed that causality patterns vary across countries and, therefore, it would be unwise to rely on inferences based on crosssection countries studies which implicitly impose crosssectional homogeneity on coefficients.

English (1998) focused on the increased production of "financial services" to construct a model in which households make purchases either with money or with costly transactions services produced by firms in the financial services sector. In his model, a higher inflation rate leads to households substituting purchased transactions services for money balances thereby boosting the size of the financial services' sector. Using crosssectional data, a test of his model established that the size of a nation's financial sector was strongly affected by its inflation rate. The results, yet again, suggested an alternative way to measure the costs of inflation.

Kim et al. (2010) employed the Pooled Mean Group estimator of Pesaran and Shin (1998) to an unbalanced panel data for 87 countries over the 1960-2005 periods and established that a negative long-run relationship coexists between inflation and financial development; with an associated positive short-run liaison. They established a strong link between inflation and financial development, irrespective of alternative financial development measures, control variables and inflation uncertainty proxies. Specifically, higher inflation appears to stymie financial development in the long run but stimulate financial markets activities in the short run. However, when splitting the data into different income or inflation groups, their results were observed only in low-income countries or low-inflation economies. In addition, the long-run impact is observed to be generally much larger than the short-run effect.

Overall, it can be concluded that available theoretical literature posits a negative relationship between inflation and financial development. Unfortunately, the conclusions appear to be mixed from the available empirical literature.

\section{MATERIALS AND METHODS}

First, to examine the relationship between inflation and financial development, the study made use of the bounds test approach to cointegration originally introduced by Pesaran and Shin (1998) and further extended by Pesaran et al. (2001). This approach was preferred to the more frequently used cointegration approach by Johansen and Juselius (1990) because of its good small sample properties and its applicability 
irrespective of whether the underlying regressors are purely stationary, purely integrated or mutually cointegrated. The cointegration approach by Johansen and Juselius (1990), on the other hand, does not have good small sample properties and inevitably involves a certain degree of pre-testing which further introduces another degree of uncertainty into its analysis (Pesaran et al., 2001).

Second, to establish the causal link between inflation and financial development, the Toda and Yamomanto (1995) causality testing procedure was made use of, instead of the more frequently used Granger Causality test-as it has two critical issues that serve as a challenge. First, the direction of causality between any two variables depends critically on the number of the lagged terms included, such that, if the chosen lag length is smaller than the true lag length, the omission of relevant lags may cause bias; conversely, the inclusion of extraneous lags in the equation may cause the estimates to be inefficient. Second, the traditional Granger causality test is based on the assumption that variables are stationary, or even if non-stationary have the same order of integration. Though the first issue could be addressed by Any of the Information Criterions (e.g., $\mathrm{AIC}$ and $\mathrm{SBC}$ ) in fixing the choice of the optimal lag length, the restrictive assumption concerning stationarity and the order of integration of variables requires the fulfilment of the sufficient rank conditions based on the models trace and its maximum eigen value. This is not easily comprehensible. The Toda and Yamomanto (1995) approach resolves the above issues and is applicable irrespective of whether the underlying variables are stationary (around a deterministic trend), integrated of an arbitrary order, or cointegrated of an arbitrary order.

Lastly, to examine the threshold relationship between inflation and financial development, the study made a simplified assumption (basically for convenience) of the existence of only a single threshold and adopted the empirical model initially utilized by Boyd et al. (2001) and later Khan and Senhadji (2006). This was because, comparably, its specification best suits the existence of a threshold and is statistically reliable. More also, the link between inflation and financial development in Ghana best reflects the behaviour of the variables employed by Boyd et al. (2001); Khan and Senhadji (2006); Boyd et al. (2001) and Khan et al. (2001).

Inflation was computed as the first difference of the $\log$ of the Consumer Price Index (CPI), while Financial Development (FD) was measured by four different indicators-the ratio of Domestic Credit of DMBs to GDP, the ratio of Private Sector Credit to GDP, the ratio of Value Traded in the GSE to GDP and the ratio of Market Capitalization to GDP-to ensure a good comparison between bank-based indicators of financial and market-based indicators. Other control variables used were balance of trade, interest rate spread, lending rate and deposit. The data was obtained from the BG (2010) and the Ghana statistical service.

\section{RESULTS AND DISCUSSION}

The cointegration test was performed to ascertain the relationship (short or long) that existed between inflation and all four indicators of financial development. Following the modelling approach by Pesaran et al. (2001), the long run relationship (cointegration) between inflation (INF) and financial development was ascertained by augmenting an Unrestricted Error Correction Model with a maximum lag of four. The optimal lag was determined by the minimum of the either the Akaike or Schwarz Bayesian information criterion. A Wald test was subsequently conducted on the lagged level variables by linearly restricting their coefficients to zero and comparing the resulting test statistic (F-statistic) with the critical values provided by Pesaran et al. (2001). To ensure conformity in the results, a series of codes (critical values) were generated using GAUSS ${ }^{\mathrm{TM}}$ for a sample of 80 with the assumption of unrestricted intercept and no linear trend to verify the bounds test results, since the critical values provided by Pesaran et al. (2001) are for relatively large samples. Table 2 presents the results of this test.

From Table 2, the computed F-statistic appears to be smaller than the $5 \%$ lower bound critical value (both for critical values obtained from Pesaran et al. (2001) and those generated specific to the samples size) for all possible parings of inflation and financial development. This suggests the absence of cointegration between inflation and the available indicators of financial development selected. In other words, there is no long run relationship between inflation and financial development in Ghana. This finding was consistent with the results of Keho (2009), who did not establish any long run relationship between inflation and financial development for almost all UEMOA countries, except Senegal.

The corresponding short-run dynamic coefficients between inflation and financial development were obtained by normalising INF on DCG, PSCG, MCG and VATG. Surprisingly, DCG, PSCG and MCG had positive influences on INF and the estimates were statistically significant (Table 1). 
Table 1. Short-run dynamic coefficients

\begin{tabular}{|c|c|c|c|c|}
\hline $\operatorname{dinf}$ & Equation 1 & Equation 2 & Equation 3 & Equation 4 \\
\hline Intercept & $-0.020(0.402)$ & $-0.030(0.205)$ & $-0.008(0.715)$ & $-0.004(0.970$ \\
\hline $\operatorname{dinf}(-1)$ & $0.390(0.002)$ & $0.371(0.003)$ & $0.444(0.000)$ & $0.387(0.003)$ \\
\hline $\operatorname{dinf}(-3)$ & $\ldots$ & $\ldots$ & $\ldots$ & $0.202(0.031)$ \\
\hline $\operatorname{dinf}(-4)$ & $-0.362(0.00)$ & $-0.369(0.000)$ & $-0.356(0.002)$ & $-0.462(0.000)$ \\
\hline $\mathrm{d} d c g(-4)$ & $0.535(0.089)$ & $\ldots$ & $\ldots$ & $\ldots$ \\
\hline $\mathrm{d} p \operatorname{scg}(-4)$ & $\ldots$ & $0.900(0.013)$ & $\ldots$ & $\ldots$ \\
\hline $\mathrm{d} m c g(-2)$ & $\ldots$ & $\ldots$ & $0.071(0.003)$ & $\ldots$ \\
\hline dvatg $(-2)$ & $\ldots$ & $\ldots$ & $\ldots$ & $0.035(0.048)$ \\
\hline $\mathrm{d}$ vatg $(-4)$ & $\ldots$ & $\ldots$ & $\ldots$ & $-0.033(0.019)$ \\
\hline R-Squared & 0.3374 & 0.3623 & 0.3533 & 0.3581 \\
\hline Adjusted R-Squared & 0.3095 & 0.3354 & 0.3260 & 0.3115 \\
\hline D-W Statistic & 2.2087 & 2.1433 & 2.2504 & 2.1499 \\
\hline
\end{tabular}

Source: Estimated with E-Views 5.1.

Note: P-Values in parenthesis

Table 2. Results of bounds test to cointegration

\begin{tabular}{|c|c|c|c|c|}
\hline \multirow[b]{2}{*}{ Dep. Var. } & \multicolumn{4}{|c|}{ Results from bounds test } \\
\hline & SBC Lags & $\mathrm{F}$ & Probability & Outcome \\
\hline$\overline{\mathrm{F}_{\mathrm{DCG}}(\mathrm{DCG} / \mathrm{INF})}$ & $(0,0)$ & 2.2839 & 0.109 & No Cointegration \\
\hline $\mathrm{F}_{\mathrm{INF}}(\mathrm{INF} / \mathrm{DCF})$ & $(4,0)$ & 3.3353 & 0.042 & No Cointegration \\
\hline $\mathrm{F}_{\mathrm{PSCG}}(\mathrm{PSCG} / \mathrm{INF})$ & $(0,0)$ & 4.8680 & 0.010 & No Cointegration \\
\hline $\mathrm{F}_{\mathrm{INF}}(\mathrm{INF} / \mathrm{PSCG})$ & $(4,0)$ & 3.0022 & 0.056 & No Cointegration \\
\hline $\mathrm{F}_{\mathrm{MCG}}(\mathrm{MCG} / \mathrm{INF})$ & $(0,0)$ & 2.5993 & 0.081 & No Cointegration \\
\hline $\mathrm{F}_{\mathrm{INF}}(\mathrm{IFG} / \mathrm{MCG})$ & $(4,0)$ & 2.4401 & 0.095 & No Cointegration \\
\hline $\mathrm{F}_{\mathrm{INF}}(\mathrm{INF} / \mathrm{VATG})$ & $(4,0)$ & 0.2037 & 0.816 & No Cointegration \\
\hline
\end{tabular}

Source: Estimated with Microfit 4. Notes: Asymptotic critical value bounds were obtained from Table F in Appendix C, Case III: unrestricted intercept and no trend for $\mathrm{k}=1$ (Pesaran and Shin, 1998). Lower bound $\mathrm{I}(0)=4.94$ and Upper bound $\mathrm{I}(1)=5.73$ at $5 \%$ significance level Lower bound $\mathrm{I}(0)=5.06$ and Upper Bound $\mathrm{I}(1)=5.96$ at $5 \%$ significance level (Critical Values were generated from GAUSSTM (Keho, 2009) Equations are augmented with White's Heteroskedasticity coefficient covariance Diagnostic Test results for these estimations are presented in Appendix C

Table 3. Results for causality test

\begin{tabular}{|c|c|c|c|c|}
\hline \multirow[b]{2}{*}{ Dep. Var. } & \multicolumn{4}{|c|}{ Results from Toda and Yamomanto (1995) causality test } \\
\hline & $\left(\mathrm{k}+\mathrm{d}_{\max }\right)$ Lags & $\mathrm{F}$ & Probability & Direction of causality \\
\hline$\overline{\mathrm{F}_{\mathrm{DCG}}(\mathrm{DCG} / \mathrm{INF})}$ & 3 & 1.8022 & 0.4061 & No \\
\hline $\mathrm{F}_{\mathrm{INF}}(\mathrm{INF} / \mathrm{DCF})$ & 3 & 0.2320 & 0.8905 & No \\
\hline $\mathrm{F}_{\mathrm{PSCG}}(\mathrm{PSCG} / \mathrm{INF})$ & 3 & 6.3871 & $0.0410 *$ & $\mathrm{INF} \rightarrow \mathrm{PSCG}$ \\
\hline $\mathrm{F}_{\mathrm{INF}}(\mathrm{INF} / \mathrm{PSCG})$ & 3 & 0.4070 & 0.8159 & No \\
\hline $\mathrm{F}_{\mathrm{MCG}}(\mathrm{MCG} / \mathrm{INF})$ & 3 & 0.5192 & 0.7714 & No \\
\hline $\mathrm{F}_{\mathrm{INF}}(\mathrm{IFG} / \mathrm{MCG})$ & 3 & 5.7330 & $0.0569 *$ & $\mathrm{INF} \rightarrow \mathrm{MCG}$ \\
\hline $\mathrm{F}_{\text {VATG }}(\mathrm{VATG} / \mathrm{INF})$ & 3 & 1.3728 & 0.8489 & No \\
\hline $\mathrm{F}_{\mathrm{INF}}(\mathrm{INF} / \mathrm{VATG})$ & 3 & 4.4519 & 0.3483 & No \\
\hline
\end{tabular}

Source: Estimated with Microfit 4 . Note: $\left.{ }^{* * *}\right)$ denotes statistical significance at the 1 and $5 \%$ respectively

Table 4. Tests for threshold level and relationships

\begin{tabular}{llllll}
\hline $\begin{array}{l}\text { Dependent } \\
\text { variable }\end{array}$ & $\begin{array}{l}\text { Search range } \\
\text { for threshold }\end{array}$ & $\begin{array}{l}\text { Estimated } \\
\text { threshold }\end{array}$ & F-statistic & Chi-square & $\begin{array}{l}\text { Significance } \\
\text { level }\end{array}$ \\
\hline DDCG & $\{1,2,3, \ldots, 100\}$ & 11 & 12.05974 & 12.05974 & 0.0010 \\
DPSCG & $\{1,2,3, \ldots, 100\}$ & 16 & 3.269185 & 3.269185 & 0.0760 \\
VATG & $\{1,2,3, \ldots, 100\}$ & 11 & 4.923835 & 4.923835 & 0.0298 \\
DMCG & $\{1,2,3, \ldots, 100\}$ & 11 & 0.848570 & 0.848570 & 0.3610 \\
\hline
\end{tabular}

Source: Estimated with E-Views 5.1. Note: Results were better without the logs of the variables, hence their omission 
Table 5. The inflation-financial development NLSS estimates

$$
\text { Dependent variable }
$$

\begin{tabular}{|c|c|c|c|c|}
\hline \multirow[b]{2}{*}{ Independent variables } & & & & \\
\hline & DDCG & DPSCG & VATG & DMCG \\
\hline$\left(1-d_{i t}^{\pi^{*}}\right)\left(1 / \pi_{i t}-1 / \pi^{*}\right)$ & $2.49(0.000)$ & $0.20(0.037)$ & $0.04(0.081)$ & $-1.57(0.411)$ \\
\hline $\mathrm{d}_{\mathrm{it}}^{\pi^{*}}\left(1 / \pi_{\mathrm{it}}-1 / \pi^{*}\right)$ & $0.02(0.526)$ & $0.001(0.984)$ & $-0.01(0.062)$ & $0.16(0.264)$ \\
\hline
\end{tabular}

Source: Estimated with E-Views 5.1. Note: P-Values are provided in parenthesis; Estimates corrected with White Heteroskedasticity-consistent standard-errors

For VATG, the relationship was uncertain (though statistically significant). These findings appear to contradict the set of theoretical literature that posits a negative association between inflation and financial development. On the other hand, it seems to support the theoretical literature of the monetarists, who see inflation to be precipitated by monetary pressures (i.e., inflation is always and everywhere a monetary phenomenon). These results further satisfy the battery of diagnostic tests described in the earlier section.

The Short-run Dynamic Coefficients (Parsimonious Error Correction Equations (A maximum lag length of four (4) was selected in specifying the equation, as quarterly data is being employed. Accompanying this, is a general-to-specific reduction of equations for parsimony) can be observed below.

To complement the above results, a causality test was conducted between inflation and the indicators of financial development using the Toda and Yamomanto (1995). The approach involves the addition of extra lags (determined by the order of integration of the series) to the lags determined by any of the information criterion to correctly specify level VAR's. This was basically to control for potential cointegration. These equations were later estimated by the seemingly unrelated regression technique. Further, a Wald test imposing a linear restriction on the appropriate kth coefficient variable susceptible of causing the other was carried out using the standard chi-squared distribution. Results of this causality tests are presented in Table 3 .

The results, as can be learned from the p-values of the Wald statistic, indicates a causality running from INF to PSCG on one hand from INF to MCG on the other hand. This causality is unidirectional and negative, implying past values of inflation has a predictive power in adversely affecting the present values of PSCG and MCG. It suggests that policies aimed at reducing the rate of inflation will particularly enhance projects that source their funds from Private Sector Credit (PSCG) and also increase participation on the stock Market (MCG). On the other hand, financial policies concerning the allocation of credit to the private sector and also boosting participation on the stock market should be taken more seriously, as PSCG and MCG had no causal effects on INF. These findings were consistent with that of Keho (2009), who established a causality running from inflation to financial development in Niger and Mali (using the ratio of credits provided by financial intermediaries to the private sector to GDP as a proxy for financial development). It also supports the group of theoretical works that posits a negative causal effect of inflation on financial development (Boyd et al., 1996; Huybens and Smith, 1999). For DCG and VATG, there was no evidence of causalities with INF.

In estimating the threshold rate of inflation, above which inflation affects financial development differently than below, the conditional least squares technique was used. This was the case since the threshold rate was unknown and must be estimated for, just like any other coefficient, before approximating the exact links between inflation and financial development (either below or above this threshold rate). The threshold estimate was the one that minimizes the sequence of RSSs. Its statistical significance is justified by imposing a linear restriction of no threshold effects (Wald test) on the two inflation-related terms: one giving the influence before the threshold rate and one after the rate. The results for these test is summarized in Table 4.

As can be observed from Table 4, the data strongly supports the existence of threshold effects in the inflation-financial development link in Ghana. This was estimated to be between $11-16 \%$ and statistically significant for DCG, PSCG and VATG; but not for MCG. These results were not very different from that of Apo (2004), who estimated a threshold of $9 \%$ in support of financial development in Ghana.

In addition, Table 5 presents the results for the exact empirical link between inflation and financial development for the above estimated threshold rates of inflation.

Three estimations in the table show statistically significant similar effects of inflation on financial development below the estimated threshold rate (i.e., for 
equations where DCG, PSCG and VATG are used as indicators of financial development). The results suggest a small increase in the rate of inflation (i.e., below the threshold rate) is accompanied by a reduction in financial development. The reductions were observed to be very modest for PSCG and VATG, while relatively large for DCG. Above the threshold rate, the effect of inflation on financial development is not very clear as the estimates were not statistically significant. This could possibly be as a result of the non-linear nature of the inflation-financial development link in Ghana. For MCG, there was no clear cut distinction. These results were consisted with the findings of Khan (2008); though they contradict on relatively fewer grounds; a result of different control variables and proxy's for financial development.

\section{CONCLUSION}

The study examined the links between inflation and financial development in Ghana. This was accomplished with three dynamic econometric models: A bivariate ARDL, a bivariate VAR a multivariate NLLS-were specified. The results, both from common correlation analysis to recent econometric modelling, indicate the following. First, there was no evidence of a cointegrating (long run) relationship between inflation and financial development in Ghana; for the short run, inflation had a positive association (relationship) with financial development. Second, a unidirectional and negative causality was established to be running from inflation to PSCG and VATG; for DCG and MCG, there was no evidence of causality with inflation. Third, the dataset (1990-2009) strongly supports the existence of threshold effects in the inflation-financial development link. The threshold range was estimated to be between $11-16 \%$. Below this range, a relatively small increase in the rate of inflation is accompanied by a very modest reduction in financial development (i.e., when PSCG and VATG are used as indicators of financial development). The reductions were relatively large for DCG, but unclear for MCG. Above the threshold rate, definite deductions could not be made, as almost all coefficients for the financial development indicators were statistically insignificant.

Based on the above findings, the following conclusions were made. First, inflation has no long run relationship with financial development in Ghana (at least for four indicators of financial development-DCG, PSCG, MCG and VATG). However, in the short run, increases in the rate of inflation are associated with subsequent increases in the level of financial development. Second, inflation causes financial development (i.e., when PSCG and VATG are used as indicators). However, for MCG and DCG, there was no evidence of a causal relationship with inflation. On the other hand, there was no causality igniting from any of the indicators of financial development to inflation. Lastly, threshold effects persist in the inflation-financial development link. This threshold is estimated to be between $11-16 \%$ points of CPI inflation rate. Below inflation rates ranging $11-16 \%$ points, increases in the rate of inflation are associated with statistically significant reductions in the level of financial development. Above the threshold range, the effects are uncertain.

It thus appears inflation presents deleterious effects to financial development in Ghana; but not the other way round. Therefore in the quest to ensuring relatively stable prices, financial sector development policies needs be taken more seriously.

\subsection{Recommendations}

Based on the above conclusions, the following policy recommendations are suggested. Accompanying these recommendations are proposed areas for further studies.

First, the current monetary policy objective of ensuring price stability should be given a high priority by monetary policy decision makers and attuned towards the definition of price stability between $11-16 \%$ points (year-on-year CPI inflation rates) in support of financial development in Ghana. This recommendation is arrived at from the conclusion that inflation presents deleterious effects to financial development below inflation rates of $11 \%$. For inflation rates above $16 \%$, the link is unclear but may not be favourable to financial development as the data established a negative relationship between the two variables.

Second, financial sector policies should be implemented in a more holistic approach (both policywise and in terms of the establishment of financial institutions and their instruments), as this does not cause the rate of inflation to either accelerate or decelerate (or ignite inflationary pressures). This stems from the fact that no statistical evidence of causality was established to be running from any of the four indicators of financial development (DCG, PSCG, VATG and MCG) to inflation. This evidence does not necessarily imply financial development (in general) may not cause inflation. Financial development could cause inflation, but perhaps for other indicators of financial development.

Lastly, the evidence of high levels of financial development (Financial development in this case captures the overall size of the financial sector, the liquidity of assets in the sector and the efficiency of the sector in the allocating resources) being consistent with inflation rates 
between 11-16\% (assuming financial development indeed promotes growth as is conjectured in the supply leading hypothesis) provides support for the theoretical positions of Huybens and Smith (1999); Rousseau and Wachtel (2002) and Lee and Wong (2005) who claimed financial development could only promote growth under low or moderate inflation rates. However, the factors that will enable this smooth transition, their definitions and what levels are considered to be appropriate could be a line of inquiry for further research.

\section{REFERENCES}

Acquah, P.A., 2005a. The monetary policy setting in Ghana-issues and prospects. ModernGhana.

Acquah, P.A., 2005b. Welcome remarks of a Bank of Ghana symposium. ACCRA.

Al-Nasser, O. and D. Jackson, 2012. The impact of financial sector performance in Latin American countries. University of Texas-Pan American.

Apo, N., 2004. Inflation and financial depth in Ghana. M.Sc. Thesis, University of Ghana.

Bencivenga, V., B. Smith and R. Starr, 1995. Transaction costs, technological choice endogenous growth. J. Econ. Theory, 67: 153-117. DOI: 10.1006/jeth.1995.1069

Bencivenga, V.R. and B.D. Smith, 1992. Deficits, inflation and the banking system in developing countries: The optimal degree of financial repression. Oxford Econ., 44: 767-790.

BG, 2002. Act 612. ACCRA, Ghana.

BG, 2010. Monetary policy report.

Bittencourt, M., 2008. Inflation and financial development: Evidence from Brazil. UNU-WIDER.

Boyd, J.H., B.D. Smith and R. Levine, 1996. Inflation and financial market performance. Pennsylvania State University.

Boyd, J.M. and B.D. Smith, 1998. Capital market imperfections in a monetary growth model. J. Econ. Theory, 11: 241-273. DOI: 10.1007/s001990050187

Boyd, J.M., R. Levine and B.D. Smith, 2001. The impact of inflation on financial sector performance. J. Monet. Econ., 47: 221-248. DOI: 10.1016/S03043932(01)00049-6

Caner, M. and B.E. Hansen, 2004. Instrumental variable estimation of a threshold model. Econ. Theory, 20: 813-843.

English, B.W., 1998. Inflation and financial market size. J. Monet. Econ.

Fischer, S., 1983. Inflation and growth. Cambridge.
Fischer, S., 1996. Why are central banks pursuing longrun price stability? J. Proc., 1: 7-34.

Ghazouani, S., 2005. Does inflation impact on financial sector performance in the MENA region? Rev. Middle East Econ. Finance, 3: 48-58.

Gockel, A.F. and S.K. Akoena, 2002. Financial intermediation for the poor: Micro, sal and medium scale enterprises in Ghana-A further assignment for financial sector policy? IFLIP Research Paper No. 02-6, ILO Geneva.

Greenspan, A., 1996. Opening Remarks: Achieving Price Stability. Proceedings of the Opening Remarks on the Federal Reserve Bank of Kansas City Symposium Achieving Price Stability, (SAPS' 96).

Huang, H.C., S.C. Lin and C.C. Yeh, 2010. Inflation and the finance-growth nexus. Econ. Modell., 27: 229236. DOI: 10.1016/j.econmod.2009.09.003

Huybens, E. and B. Smith, 1998. Financial market frictions, monetary policy capital accumulation in a small open economy. J. Econ. Theory, 81: 353-400. DOI: $10.1006 /$ jeth. 1997.2372

Huybens, E. and B.D. Smith, 1999. Inflation, financial markets long-run real activity. J. Monet. Econ., 43: 283-315. DOI: 10.1016/S0304-3932(98)00060-9

Johansen, S. and K. Juselius, 1990. Maximum likelihood estimation and inference on cointegration-with applications to the demand for money. Oxford Bull. Econ. Stati., 52: 169-210. DOI: 10.1111/j.14680084.1990.mp52002003.x

Keho, Y., 2009. Inflation and financial development: Cointegration and causality analysis for the UEMOA Countries. Int. Res. J. Finance Econ., 1: 118-123.

Khan, M.S. and A.S. Senhadji, 2001. Threshold effects in the relationship between inflation and growth. IMF Staff Paper, 48: 1-21.

Khan, M.S. and A.S. Senhadji, 2006. Threshold effects in the relationship between inflation and growth. Social Science Electronic Publishing, Inc.

Khan, M.S., 2008. Financial deepening, inflation and economic growth. University of Basel.

Khan, M.S., A.S. Senhadji and B.D. Smith, 2001. Inflation and Financial Depth. 1st Edn., International Monetary Fund, pp: 30.

Kim, D., S. Lin and Y. Suen, 2010. Dynamic relationship between inflation and financial development. J. Econ. Litera., 14: 343-364.

Lee, C.C. and S.Y. Wong, 2005. Inflationary threshold effects in the relationship between financial development and economic growth: Evidence from Taiwan and Japan. J. Econ. Dev., 30: 49-70. 
Levine, R., N. Loayza and T. Beck, 2000. Financial intermediation and growth: Causality and causes. J. Monet. Econ., 46: 31-77. DOI: 10.1016/S03043932(00)00017-9

McDonough, W.J., 1997. A framework for the pursuit of price stability. Econ. Policy Rev., 3: 1-7.

McKinnon, R.I., 1973. Money and capital in economic development. 1st Edn., Washington, DC, Brookings Institution Press, ISBN-10: 0815756135, pp: 184.

McKinnon, R.I., 1982. The order of economic liberalization: Lessons from Chile and Argentina. Carnegie-Rochester Conf. Series Public Policy, 17: 159-186.

Meltzer, T.C., 1997. To conclude: Keep inflation low and, in principle, eliminate it. Louis Q. Rev., 79: 3-8.

Papademos, L., 2006. Price stability, financial stability and efficiency and monetary policy. Proceedings of the 3rd Conference of the Monetary Stability Foundation on Challenges to the Financial SystemAgeing and Low Growth, (LG' 06), Frankfurt BIS, pp: 1-8.
Pesaran, M.H. and Y. Shin, 1998. An Autoregressive Distributed Lag Modelling Approach to Cointegration Analysis. In: Econometrics and Economic Theory in the 20th Century, Strom, S. (Ed.), Cambridge University Press, ISBN-10: 0521633656, pp: 134-150.

Pesaran, M.H., Y. Shin and R.J. Smith, 2001. Bounds testing approaches to the analysis of level relationships. J. Applied Econ., 16: 289-326. DOI: 10.1002/jae.616

Rousseau, P.L. and P. Wachtel, 2002. Inflation thresholds and the finance-growth nexus. J. Int. Money Finance, 21: 777-793.

Stiglitz, J.E. and A. Weiss, 1981. Credit rationing in markets with imperfect information. Am. Econ. Rev., 53: 393-410.

Toda, H.R. and T. Yamamoto, 1995. Statistical inference in vector autoregressions with possibly integrated processes. J. Econ., 66: 225-250. DOI: 10.1016/0304-4076(94)01616-8

Volcker, P.A., 1983. We can survive prosperity. Joint San Francisco, California. 